\title{
Comparative Study about Influence of Earthworm Composting and Aerobic Composting on Biogas Residue
}

\author{
Huang Xiaohong, Jiao Jing*, Du Jihua, Li Zunxiang, Wang Shuo, Wang Jinli, \\ Guo Changjin
}

\author{
Institute of Agricultural Machinery, Chinese Academy of Tropical Agricultural Sciences \\ (CATAS),Zhanjiang 524091, Guangdong, P.R. China \\ xiaohong0611@163.com, eddweiss@163.com, dujihua050609@163.com,
}

\begin{abstract}
Key words: earthworm, aerobic composting, biogas residue
Abstract. Biogas residues were treated by earthworm composting and aerobic composting. The changes in organic matter, rapidly available nitrogen, rapidly available phosphorus and rapidly available potassium of biogas residues after the treatment by the two composting methods were measured to study the influence of different composting methods on biogas residue effect. The results show that biogas residues accord with the standards of organic fertilizer after the treatment by earthworm composting and aerobic composting. From the perspective of nutrient substances, earthworm composting is superior to aerobic composting.
\end{abstract}

\section{Introduction}

2016-2020 Investment Analysis and Prospect Forecast Report on Biogas Industry in China indicates that the central government will further increase the investment in rural biogas during the " $13^{\text {th }}$ Five-year Plan". As the national policy supports and encourages biogas industry, the number of biogas projects is on the rise, and the discharge volume of biogas residue also increases. If the plenty of biogas residue liquid discharged by biogas projects is not rationally transformed and utilized, secondary non-point source pollution and resource waste will inevitably be caused. This becomes a problem which hinders the development of biogas industry. Biogas residues are rich in organic matters and mineral elements such as nitrogen, phosphorus and potassium. Besides, they also contain multiple microelements, hydrolytic enzymes, amino acids, organic acids and auxins etc. Biogas residues can not just improve soil environment of crops, but also provide organic and inorganic nutrients, enhance physiological activity of crops, increase stress resistance of crops and improve quality of crops. Therefore, biogas residue is a good raw material of organic fertilizer.

In this study, biogas residue serves as the object of study. High-temperature aerobic composting method (in the decomposition process, organic matters were degraded, and $50 \sim 70^{\circ} \mathrm{C}$ high temperature formed, so pathogenic microorganism, parasite, various worm eggs and weed seeds could be killed) [1] and earthworm composting method (organic matters were hydrolyzed by mechanical lapping or multiple excretive enzymes [2]; besides, there was the ability to gather heavy metals [3]) were adopted to treat biogas residues. The influence of two composting methods on biogas residue effect was analyzed and compared to provide theoretical foundation for utilization of biogas residues as a fertilizer.

\section{Materials and methods}

Experimental materials. The biogas residues used for the experiment came from the residues of dry fermentation at the biogas production base of Research Institute of Agricultural Machinery under Chinese Academy of Tropical Agricultural Sciences. The basic physical and chemical properties are as follows: in the biogas residue, organic matter content $53.69 \%$, total nitrogen $2.29 \%$, 
rapidly available nitrogen $1407.02 \mathrm{mg} / \mathrm{kg}$, rapidly available phosphorus $34486.1 \mathrm{mg} / \mathrm{kg}$, rapidly available potassium $15042.3 \mathrm{mg} / \mathrm{kg}$, and $\mathrm{pH} 7.97$. The sugarcane leaves were collected from dry yellow leaves of sugarcanes at Mazhang District in Zhanjiang City, bundled and saved. During using the leaves, the leaves were smashed into $5 \mathrm{~cm}$ fragments or below (moisture content $13.00 \%$, C\% 67.85\%, N\% 0.46\%).

Composting devices. Aerobic composting device: the material is thickened woven bag, with the specification of $100 \mathrm{~cm} \times 100 \mathrm{~cm} \times 100 \mathrm{~cm}$. There are small holes in the lower, middle and lower parts of the bag for sampling, temperature and moisture measurement.

Earthworm composting device: the material is pp plastic case, with the specification of $80 \mathrm{~cm} \times 60 \times 40 \mathrm{~cm}$. There are small holes on the four sides of the case. The top and periphery of the case were pasted with non-woven fabrics to shield the light. This can get ventilation and prevent mosquitoes and earthworms from going in and out.

Experiment design. Treatment with earthworm composting: sugarcane leaves were used as the conditioner. After the biogas residues and sugarcane leaves were mixed evenly according to the mass ratio of $6: 1$, the mixture was placed for $15 \mathrm{~d}$. In this period, the mixture was stirred at the interval of $3 \mathrm{~d}$ until the temperature no longer rose. Then, earthworms were added for composting for $25 \mathrm{~d}$. In order to investigate the direct treatment effect of earthworm composting on biogas residues, moisture content and temperature were not controlled in the experimental period under the condition of guaranteeing earthworms' normal survival conditions, and the temperature measured was environment temperature.

Treatment with aerobic composting: in accordance with the experimental results in the early stage, the biogas residues and sugarcane leaves were mixed evenly according to the mass ratio of 6:1, and the mixture was placed in the self-made aerobic composting device for aerobic composting. The experiment cycle was $40 \mathrm{~d}$. In this period, the mixture was turned over once per week to make all materials fermented uniformly. When the temperature of materials drop below $30{ }^{\circ} \mathrm{C}$ and no longer rose, water spray was stopped. The experiment ended when moisture content decreased below $30 \%$.

Test items and methods. Gravimetric method was adopted to measure moisture content [4]. The ultraviolet spectrophotometer was used to measure rapidly available nitrogen. The atomic spectrophotometer was used to measure rapidly available phosphorus. The flame photometer was used to measure rapidly available potassium.

\section{Results and analysis}

Dynamic temperature change of the compost. As an important parameter of compost putrescibility, temperature change of the compost could directly reflect the activity of microorganism in the composting process and the change of composting process [5].

The process of aerobic composting is as follows: microorganism decomposed organic matters in the compost, synthesized the components of cells and generated much heat to make the temperature of compost rise. As the time of composting extended, organic matters available decreased and microbial decomposition efficiency also declined. The diffused heat was greater than the generated heat, and the temperature dropped until the temperature of the compost tended to be stable. As shown in Fig.1, indoor temperature has little influence on the process of aerobic composting. Primary and secondary processes of aerobic composting are relatively obvious. In other words, $1 \sim 17 \mathrm{~d}$ is the primary fermentation stage, and the temperature maintains above $50^{\circ} \mathrm{C} ; 18 \sim 40 \mathrm{~d}$ is the secondary fermentation stage, and the temperature presents the gradual decline trend. According to the requirements of Sanitary Standard for the Non-hazardous Treatment of Night Soil (GB7959-87), 
if the highest temperature of compost reaches $50 \sim 55^{\circ} \mathrm{C}$ or above and maintains it for $5 \sim 7 \mathrm{~d}$, or he highest temperature of compost exceeds $55^{\circ} \mathrm{C}$ and maintains it for $3 \mathrm{~d}$, non-hazardous treatment requirement is reached. Thus, aerobic composting reaches non-hazardous standard.

In the process of earthworm composting, the decomposition of organic matters in the biogas residue improved, and physical and chemical properties of biogas residues changed through synergistic effect of earthworms and microorganism so as to improve the effect. Since living life involved, indoor temperature was adopted in the composting process, without temperature intervention. Environment temperature changed a lot, but the temperature maintained the optimal temperature range for earthworms, i.e. $15^{\circ} \mathrm{C} \sim 25^{\circ} \mathrm{C}$. Thus, a good treatment effect could be gained.

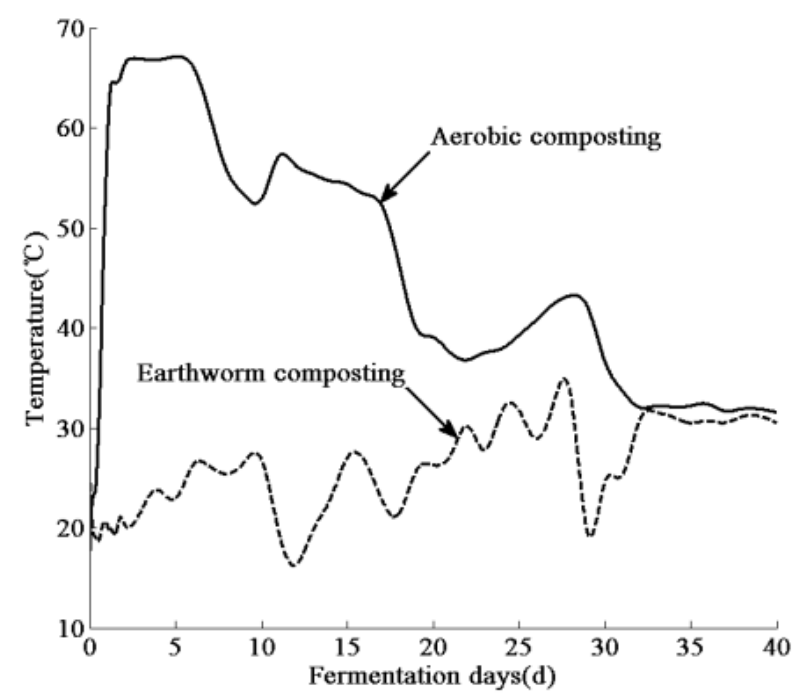

Fig.1. Dynamic temperature change of compost

Nutrient substance change before and after different composting treatment methods. The organic matter is a substance that microorganism survives on, so its change can well reflect the action of different composting methods on the compost and also reflect maturity condition of the compost. As shown in Fig.2, degradation degree of earthworm composting for organic matter is higher than that of aerobic composting, and both methods are higher than organic matter content $(\geq 45 \%)$ required by national organic fertilizer standard (NY525-2012 Organic Fertilizer). This indicates that the two composting methods are feasible, but earthworm composting shows higher degradation rate.

Total nitrogen is the sum of organic nitrogen and inorganic nitrogen of soil. As one of main indicators of soil fertility, total nitrogen content of biogas residues represents the total reserve of nitrogen and nitrogen supply capacity. In the process of high-temperature aerobic composting, nitrogen may be easily volatilized and lost in the form of ammonia gas. Earthworms will utilize nitrogen in biogas residues to synthesize their living matters. In the whole composting process, a part of nitrogen will escape in the form of NH3, thus leading to nitrogen loss. Fig.2 shows earthworm composting method has smaller total nitrogen loss than aerobic composting.

Rapidly available nitrogen is also called alkali-hydrolyzable nitrogen and hydrolyzable nitrogen, including inorganic nitrogen and organic nitrogen which has simple structure and can be directly absorbed by crops. Rapidly available nitrogen can be absorbed and utilized recently by crops. Besides, rapidly available nitrogen is an important indicator of organic fertilizer. As shown in Fig.2, the content of rapidly available nitrogen increases after the treatment with earthworm composting, compared with aerobic composting. Thus, it is believed that lapping action of earthworms promotes 
mineralization of organic nitrogen and release of inorganic nitrogen. In addition, composting under the normal temperature can control the escape of nitrogen to certain degree.

After the treatment with earthworm composting, the content of rapidly available phosphorus and rapidly available potassium in biogas residues rises, and the increment is higher than that of aerobic composting. From the perspective of nutrient substances, the effect of earthworm composting is superior to that of aerobic composting.

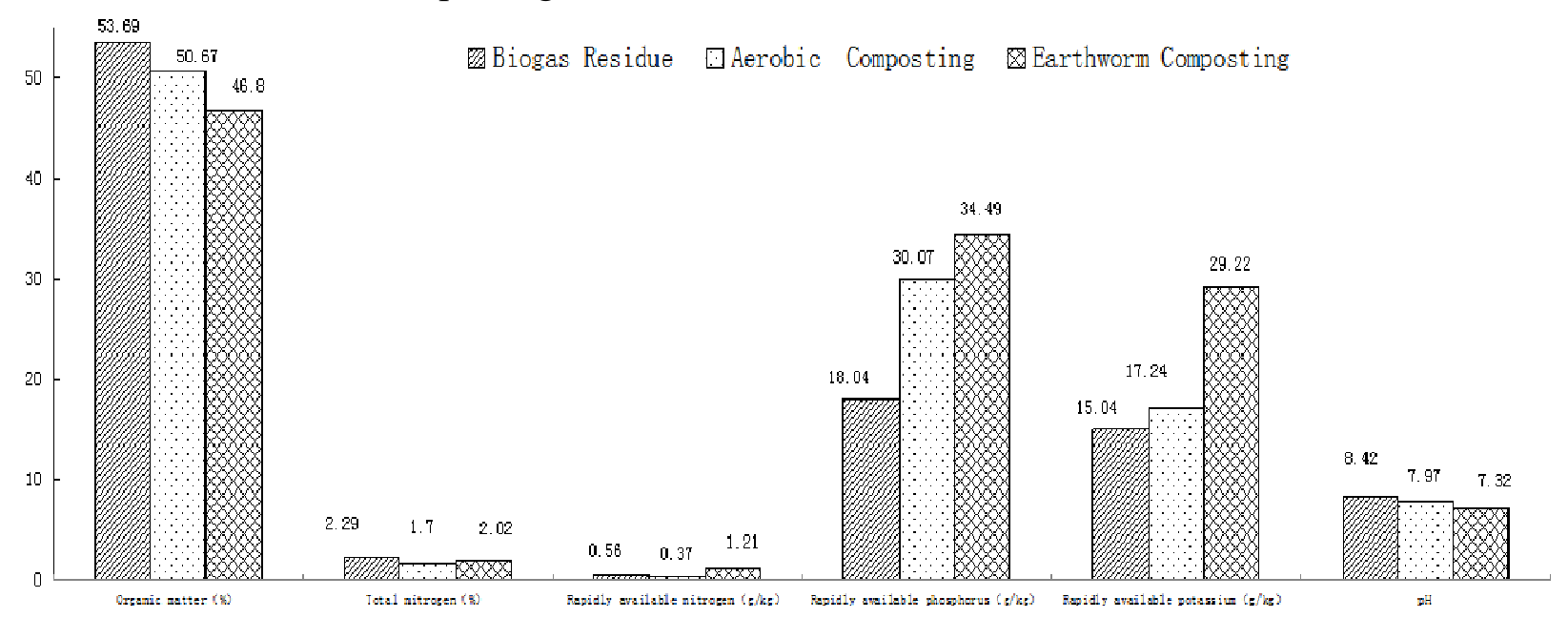

Fig.2 nutrient substance change before and after treatment with different composting methods

\section{Conclusion}

Temperature rise speed of aerobic composting is fast, and the temperature is higher than $50^{\circ} \mathrm{C}$ for 17d. Thus, it meets the requirements of Sanitary Standard for the Non-hazardous Treatment of Night Soil (GB7959-87). Moreover, it is convenient to operate and simple to manage, with low cost. After the treatment, some organic matters can be degraded, and the content of rapidly available phosphorus and rapidly available potassium rises. Therefore, aerobic composting is feasible for biogas residue composting.

After the treatment with earthworm composting, the content of rapidly available nitrogen, rapidly available phosphorus and rapidly available potassium rises. The degradation rate of organic matters improves, and composting under normal temperature makes the loss rate of nitrogen reduce. After he treatment, alkalescence of biogas residues is neutralized, and the effect improves. So, earthworm composting is also a good method. But, since the living life plays a role in the earthworm composting, it has the defect of strict production and management requirements.

\section{Acknowledgements}

This project is supported by Hainan Natural Science Fund Program (No.20163116), and Central Public-interest Scientific Institution Basal Research Fund for Chinese Academy of Tropical Agricultural Sciences (No.1630132017007).

\section{References}

[1] Ren Tiantian, Chen Jing and Liu Naizhi et al., Research Progress about Aerobic Composting Technology of Pig Manure [J]. Guangdong Feed, Vol.2(24), p.44-47 (2015).

[2] Feng Chun and Wang Longmian, General and High-temperature Pretreatment of Sludge Earthworms Composting Research [J]. Journal of Anhui Agricultural Sciences, Vol. 41 (19), p.8149-8152 (2013). 
[3] $\mathrm{Pu}$ Jisheng. Disposal and Utilization Research of Urban Sludge Treatment Plant Sludge[D]. Master Degree Theses of Master of China Excellent Full-text Database, Engineering Science and Technology I: B027-186(2007).

[4] Feng Lei, BENHARD RANINGER and Li Rundong et al., The Experiment Research of BMW (Bio-organic municipal waste) Vermicomposting Treatment [J]. Jiangsu Environmental Science and Technology, Vol.19(4), p.10-12 (2006).

[5]Li Ming. High temperature compost and worm composting of urban sludge in the form of heavy metals[J]. Journal of Environmental Engineering, Vol.2(10), p.1408-1412(2008). 